\title{
Causalidad y daño por productos defectuosos a propósito de los casos DES en los Estados Unidos*
}

\author{
Causation and Damages for Defective \\ Products about DES Cases in the United \\ States
}

Olenka Woolcott

Fecha de recepción: 18 de marzo 2009 Fecha de aprobación: 30 de abril de 2009

\section{Resumen.}

Los casos Derechos Económicos y Sociales DES en los Estados Unidos han dado lugar a diversas teorías que tratan de responder al problema de la determinación del nexo causal, como la teoría de la responsabilidad, según la participación en el mercado. Sin embargo, los intentos parecen llevar a exonerar a la víctima de probar el nexo causal y, de esta manera, el productor se transformaría en una suerte de asegurador por daños ocasionados por otros. Frente a la dificultad de determinación del nexo causal que puede surgir en otros productos además de los medicamentos, las teorías fundadas sobre una concepción probabilística de la causalidad pueden hallar nuevos campos de aplicación.

\section{Palabras clave}

Responsabilidad, daño, causalidad, productos defectuosos, causa probabilística.

\footnotetext{
Publicado en: I grandi orientamenti della giurisprudenza civile e commerciale. Collana diretta da F. Galgano. I fatti illeciti. III Causalità e danno. A cura di Giovanna Visintini. Cedam. 1999. pp. 866-894. Traducido del italiano por Luis Cárdenas Rodríguez. Profesor de Derecho Civil de la Universidad Privada Los Ángeles. Miembro del Instituto de Estudios Críticos (IEC). Se mantiene la forma de citación original.
} 


\begin{abstract}
DES cases in the United States have led to various theories that try to respond to the problem of determining causal link, such as the theory of responsibility according to market share. However, the attempts seem to exonerate the victim to prove causal link, so the producer would be transformed into a sort of insurance for damage caused by others. Faced with the difficulty of determining the causal link that can arise in other products besides drugs, theories based on a probabilistic conception of causality can find new fields of application.
\end{abstract}

\title{
Key words
}

Responsibility, damages, causal link, defective products, probabilistic cause.

\section{INTRODUCCIÓN}

En el ámbito de la temática de la responsabilidad del productor una cuestión que ha suscitado particular atención en los juristas en los últimos años: la relativa a los riesgos que se verifican durante el espacio de tiempo que corre entre el momento en que se introduce un producto en el mercado y el momento en que se verifica el daño. El tiempo transcurrido juega un rol decisivo en la evaluación de los elementos que llevará a la determinación de la responsabilidad. En efecto, si un producto no es defectuoso, de acuerdo con el estado de los conocimientos técnicos y científicos del momento en que ha sido introducido en el mercado, puede suceder que luego del desarrollo de tales conocimientos, dicho producto se revele como defectuoso.

El problema se ha planteado, fundamentalmente, en relación con los productos químicos y farmacéuticos, a la luz de la posición asumida por una reciente jurisprudencia, especialmente norteamericana.

Los interrogantes que los juristas se plantean en materia de causalidad en el ámbito de la responsabilidad del productor aumentan cuando se descubre que los daños son ocasionados por productos como el DES.

DES o diethylstibesterol es un fármaco que sirve para prevenir el aborto. En 1947 la Food and Drug
Administration en los Estados Unidos autorizó la comercialización del DES, pero sólo con fines experimentales. En las décadas del setenta y de ochenta las Cortes norteamericanas tuvieron que afrontar numerosos casos de DES (cfr. J. Page, Generic product risks, the case against comment $k$ and for strict tort liability, en New York University Law Review, 1983, pp. 853 ss.).

Los DES cases son conocidos y revisten particular importancia no sólo porque se refieren a un número relevante de víctimas, que luego de algunos años sufrieron las consecuencias dañosas de la ingesta de tal medicina, sino también por las complejas y delicadas cuestiones que presentan. Entre éstas interesa, de modo particular, la referida al nexo de causalidad.

En todos los casos DES las hijas de las mujeres que habían ingerido el fármaco DES durante el embarazo para prevenir el aborto, presentaron demandas de resarcimiento del daño sufrido. Las demandantes sostenían, como fundamento de su acción dirigida contra numerosas casas farmacéuticas productoras de DES, que el fármaco era dañino y que ellas mismas habían sido dañadas. Las demandantes presentaban diversas formas concerígenas como consecuencia de la ingesta del DES por parte de sus madres. Pero la mujeres embarazadas que ha- 
bían consumido el fármaco lo habían hecho cerca de veinte años antes de verificarse los daños en las hijas.

Frente a estos casos las Cortes norteamericanas debieron decidir si aplicar o no las reglas clásicas sobre la causalidad. En efecto, según la doctrina tradicional en materia de responsabilidad civil, el examen de la causalidad presupone la identificación del dañante para poder operar la imputación del daño (v. R.W. Wright, Caution in tort law, en Cal. L. Rev., vol. 73, n. 6, California, 1985).

En los casos DES, las demandantes se encontraron en la imposlibilidad de individualizar la casa farmacéutica que había puesto en el mercado los productos DES utilizados. De hecho, eran más de una centena las casas farmacéuticas que habían puesto en el mercado tal medicina. Por ende, el problema fundamental frente al cual se encontraron las cortes norteamericanas fue la individualización del responsable.

En lo que sigue, el examen se detendrá en la responsabilidad objetiva del productor farmacéutico por defecto de proyecto a la luz del derecho norteamericano. En este examen se pondrán de relieve las dificultades que han debido afrontar las cortes de California en la solución de los casos DES.

Antes que nada se hará una breve ilustración del contexto doctrinal y jurisprudencial en los Estados Unidos madurado sobre la llamada "products liability".

\section{DESARROLLO DE LA "PRODUCTS LIABILITY" EN LOS ESTADOS UNIDOS}

El nacimiento de la moderna responsabilidad del productor en los Estados Unidos viene atribuida a una opinión del juez Cardozo en 1916 en una sentencia de la Corte de Apelación de New York en el caso MacPherson vs. Buick Motor Co. (217 N.Y. 382, 111 N.E. 1050 (1916). En este caso los jueces hicieron una excepción a la regla de la privity of contract y establecieron que "el deber de salvaguardar la vida, cuando las consecuencias de la negligencia pueden ser previstas, va más allá del contrato..." (Id. 390, 111 N.E., 1058-1059).

El caso MacPherson fija la orientación de la jurisprudencia norteamericana en materia de responsabilidad del productor por cerca de cuatro décadas (para la situación anterior cfr. D. Leebron, An Introduction to Products Liabuility: Origins, Issues and Trenes, en Annual Survey of American Law, Oceana Publications, Inc. N.Y., 1993).

La responsabilidad objetiva hace su aparición en una concurring opinion del juez Traynor en el caso Escola vs. Coca Cola Bottling Co. (24 Cal. 2d 453, 150 P.2d 436 [1944]). El juez Traynor sostuvo que un productor debería ser considerado responsable por la introducción de un producto defectuoso en el mercado cuando hubiera conocido del hecho que sería usado sin control o bien cuando hubiera resultado que un defecto del producto causaría un daño. En la base de la tesis de Traynor está la convicción de que el productor está en grado de soportar los riesgos en cuanto se puede asegurar y distribuir el costo entre los consumidores, además de ser de interés público desincentivar la comercialización de productos defectuosos.

La teoría de la responsabilidad absoluta del juez Traynor fue adoptada parcialmente en el caso Greenman vs. Yuba Power Prods. Inc. (1963) 59 Cal. 2d. 57, 60, 477 P.2d 897, 899, 27 Cal. Rptr. 697, 699 (1963), en el cual la Corte Suprema de California se pronunció en el sentido de una strict liability.

Dos años después de la decisión del caso Greenman, el American Law Institute adoptó la teoría de la responsabilidad objetiva en la sección 402A del Restatement (Second) of torts en los términos siguientes:

La sección 402A del Restatement (Second) of torts dispone: 
(1) Quien vende un producto en condiciones defectuosas y peligrosas de modo irrazonable para el usuario o el consumidor o para las cosas que le pertenecen, es responsable del daño físico de tal modo ocasionado al consumidor o al usuario o a sus cosas, si:

a) el vendedor desarrolla actividad de venta de aquel producto, $y$

b) si uno puede esperar que el producto llegueal usuario oal consumidor en las mismas condiciones en las cuales ha sido vendido.

(2) La regla contenida en el primer párrafo de aplica aunque:

a) el vendedor haya desplegado toda la diligencia posible en la fabricación y en la venta del producto, $y$

b) el usuario o el consumidor no hayan adquirido directamente del vendedor o no hayan instaurado relaciones contractuales directas con él.

En el comentario a la sección 402A, los compiladores del Restatement explican así la naturaleza y el ámbito de aplicación de la responsabilidad del productor:

a) Este artículo establece una regla especial que se aplica a los vendedores de productos. La regla impone una responsabilidad objetiva, porque hace responsable al vendedor frente al usuario o consumidor incluso en las hipótesis en que haya observado toda la diligencia posible en la preparación o en la venta de los productos [...]. La regla aquí prevista no es, empero, exclusiva, en el sentido en que ella no precluye la posibilidad de fundar la responsabilidad del vendedor sobre la culpa, en el supuesto en que la culpa del vendedor sea probada.

[...] c) La justificación de esta regla, usualmente, reposa sobre el hecho de que el vendedor, vendiendo su producto para el consumo, asume una especial responsabilidad frente a aquellas personas que pueden ser dañadas por el producto; que el público tiene derecho a esperar que el vendedor asuma la responsabilidad de los daños, cuando ellos deriven de productos que el público adquiere para satisfacer una necesidad propia, confiando en el vendedor; que la sociedad requiere que el peso de los accidentes provocados por los productos destinados al consumo grave sobre aquéllos que los ponen en venta, y sea considerado como un costo de producción contra el cual el vendedor puede asegurarse; en fin, que el consumidor de tales productos debe tener la máxima protección, y las personas que se la pueden asegurar son aquéllas que comercilizan aquellos determinados productos.

[...] f) La regla no se aplica, obviamente, a aquéllos que son vendedores solamente ocasionales de tales productos y no desarrollan esta actividad como actividad profesional a la que se dedican. Por eso, no se puede aplicar, por ejemplo, a la ama de casa que vende un frasco de mermelada o un poco de azúcar a su vecina de casa. $\mathrm{Ni}$ al propietario de un automóvil que lo vende a su vecino o a un revendedor de autos usados, no obstante el vendedor ocasional sepa que el intermediario, a su vez, revenderá el auto a terceros.

[...] g) La regla precisada en este artículo se aplica sólo en el caso en que el producto, al momento en que ha dejado las manos del vendedor, esté en condición de peligro desconocida por el consumidor y tal que constituya un peligro irrazonable para él. El vendedor no es responsable si entrega un producto en buenas condiciones, y el producto deviene luego defectuoso por razones debidas a errada conservación o manipulación de los intermediarios. (The American Law Institute, Restatement of the Law, Second, Torts, 2d., vol. 2, St. Paul Minn., 1965, p. 348 ss.).

\section{LA STRICT LIABILITY: FUNDAMENTOS}

Cuando la responsabilidad objetiva aparece por primera vez en las decisiones de las cortes de los Estados Unidos en 1963 viene basada en los siguientes fundamentos: 1) el productor se encuentra en una posición mejor respecto de los consumidores para asegurarse. Estos fundamentos se encuentran en la base de las sentencias dadas por las Cortes norteamericanas después del caso Greenman. Tales argumentaciones han logrado influir todo el derecho privado norteamericano (v. G. Priest, 
La scoperta della responsabilità d'impresa: una storia critica delle origini intelettuali del moderno sistema della responsabilità civile, en Resp. civ. e prev., 1985, p. 275 ss.).

La situación referida ha conducido al derecho civil norteamericano a un estado de crisis. De hecho, si, por un lado, hay grandes incentivos para la aseguración de los hechos dañosos no fácilmente previsibles y, por otro lado, prevalece la opinión según la cual el productor es siempre el más idóneo para prevenir los riesgos, resulta que los productores serán siempre responsabilizados más frecuentemente. En realidad, las Cortes se orientaron hacia la aplicación de reglas de responsabilidad objetiva absoluta.

La responsabilidad objetiva prescinde sea de la negligencia, sea de una relación contractual directa entre productor y consumidor. Pero no elimina todos los problemas de prueba. El actor debe demostrar que el demandado le ha procurado un producto que no debía ser puesto en comercio, un producto que le ha provocado un daño. Esto queire decir que él debe probar no sólo el daño sufrido, sino también el nexo de causalidad entre el daño y el defecto del producto. La simple "posibilidad" de que el daño se verifique no basta.

El actor debe probar que el daño sufrido ha sido ocasionado por un defecto del producto o que el producto no era inocuo por otras razones (Prosser, The Fall of the Citadel, p. 840 ss.). Por tanto, la carga de la prueba de que el autor ha sufrido una lesión a causa del producto defectuoso grava sobre él. Para obtener el resarcimiento del daño con la escolta de la strict liability según la sección 402A del Restatement (Second) of torts, el producto debe ser defectuoso e irrazonablemente peligroso.

Por tanto, a los efectos del resarcimiento del daño por producto, el actor debe demostrar la existencia del nexo de causalidad y la preexistencia del defecto al momento de haberse puesto en comercio el producto. El hecho de que en la responsabilidad objetiva no se deba probar la culpa del demandado no quiere decir que se pueda omitir la prueba de la relación de causalidad. En caso contrario nos encontraríamos frente a una "responsabilidad absoluta". Esta última, en efecto, prescinde de la prueba del nexo de causalidad. En realidad, esta forma de responsabilidad, no justificada a la luz de las reglas de la responsabilidad civil, transforma al demandado en una suerte de asegurados (cfr. Platt \& Platt, Moving from Strict to Absolute Liability, Nat'I L.J., jan. 17, 1983, at 15, col. 3, 18).

\section{RESPONSABILIDAD DEL FABRICANTE DE PRODUCTOS MEDICINALES}

Los casos DES han Ilamado la atención sobre la investigación acerca de la causalidad. En efecto, en estos casos se presenta la dificultad de individualizar al responsable de los daños ocasionados por los productos puestos en el mercado años atrás, con la consecuencia de determinar un número vasto de víctimas.

Volviendo a la sección 402A del Restatement (Second) of Torts, el cual prevé la responsabilidad objetiva del productor, es oportuno notar que antes de la aprobación de esta normativa, los miembros del American Law Institute se detuvieron sobre la cuestión de si era posible o no sustraer los productos medicinales a la aplicación de la strict liability. Si bien el ALI no estuvo de acuerdo con dicha exclusión, Prosser, uno de los grandes artífices del desarrollo de la responsabilidad objetiva en los Estados Unidos y miembro de la Corte Suprema de California en el caso Greenman en 1961 elaboró el proyecto inicial de la sección 402A del Restatement (Second) of torts. Sobre aquel proyecto se escribió que la normativa sólo se aplicaría a los productos alimenticios. Pero en 1965 el proyecto definitivo de la sección 402A fue aprobado, y este texto no limita su aplicación a los productos alimenticios. En particular, se redactó un comment en relación con los productos medicinales. Se trata del com- 
ment $k$ a la sección 402A. Este comment refleja las preocupaciones compartidas por el autor sobre el hecho de que los productores de ciertas medicinas "inevitablemente inseguras" puedan ser considerados objetivamente responsables. El Instituto aprobó la sección 402A junto con el comment $k$ ( $v$. J.C. Kelso, Brown v. Abbott Laboratories and Strict Products Liability, en Pacific Law Journal, vol. 20, n. 1,1988, p. 13 ss.).

\section{El comment k prevé:}

k. productos inevitablemente peligrosos. Existen algunos productos que en el estado actual de los conocimientos humanos, no es posible dar por seguros para el uso previsto y ordinario. La mayor difusión de estos productos se verifica en el campo de las medicinas. Un claro ejemplo nos lo da la vacuna Pasteur anti rabia, que no raramente, cuando es inyectado, acarrea consecuencias bastante serias y peligrosas. Desde el momento que la enfermedad, de todos modos, lleva a una muerte terrible, la comercialiciación y el uso de la vacuna están plenamente justificados, pese al alto porcentaje de riesgo que conllevan. Dicho producto, expresamente preparado y acompañado de específicas instrucciones y advertencias, no es defectuoso y ni siquiera irrazonablemente peligroso. Lo mismo vale para muchas otras medicinas, vacunas $y$ similares, muchas de las cuales, por este grave motivo, pueden ser adquiridos sólo por los médicos o bajo su prescripción. Y esto es verdad, en particular, para muchos fármacos, nuevos o experimentales, para los cuales, por falta de tiempo o de oportunidades de experimentación médica 0 también por incertidumbres acerca de los ingredientes, no se puede garantizar su seguridad, sino en la medida en que la experimentación desarrollada consiente su comercialización y uso aun en presencia de un riesgo latente. El vendedror de tales productos, siempre que éstos hayan sido preparados y vendidos correctamente y dotados de correctas advertencias, no puede ser considerado como objetivamente responsable por las consecuencias dañosas que deriven de su uso, principalmente porque él se ha comprometido a proveer un producto aparentemente útil y deseable, acompañado de un riesgo concido pero aparentemente razonable (v. J. Page, Generic product risks: The case against comment $k$ and for strict tort liability, en New York University Law Review, n. 4, New Jersey, 1983, p. 855).

El comment $k$ ha sido criticado y analizado por muchos; si, por una parte, no existe consenso acerca de su ámbito de aplicación y su significado, por otra parte, en cambio, hay concordancia de opiniones sobre el hecho de que si bien mira a aclarar la doctrina de la responsabilidad objetiva, en la práctica el principio que atestigua está basado sobre la negligence. Es decir, el comment $k$ impondría la responsabilidad de un productor farmacéutico sólo si éste deja de advertir acerca de un defecto que conoce o que, de todas maneras, habría debido conocer. El punto central de este concepto no es la carencia del producto -el flucro de la responsabilidad objetiva-, sino la culpa del productor por no haber dado a conocer los peligros inherentes al uso del producto que conocía o habría debido conocer - una idea que "sabe de negligencia" - en palabras del caso Cronin (Cronin v. J.B.E. Olson Corp. 8 Cal. 3d. 121, 501 P. 2d 1153, 104 Cal. Rptr. 433 [1972]).

El comment $k$ ha sido adoptado por la mayoría de las Cortes norteamericanas (el comment $k$ ha sido, asimismo, recepcionado por la ley de New Jersey de 1987 sobre la responsabilidad por productos y constituye un paso importante en la así llamada contrarrevolución del derecho civil estadounidense) (cfr. G. Priest, La controrivoluzione nel diritto della responsabilità da prodotti negli Stati Uniti d'America, trad. bajo el cuidado de Giulio Ponzanelli, en Foro it., 1989, IV, c. 119), pero sin que se haya llevado adelante un examen detallado de su formulación. De ahí que algunos han condicionado la aplicación de la excepción descrita con respecto a la regla establecida en la sección 402A del Restatement (Second) of torts sobre la responsabilidad objetiva al hecho de que el medicamento involucrado sea "inevitablemente 
peligroso" (véase J. Page, Generic Product Risks..., cit., p. 867). Otros han sostenido que la excepción contenida en el comment $k$ no debe ser limitada a los medicamentos subordinados a prescripción médica (de hecho, la propuesta de no considerar en la excepción prevista por el comment $k$ a los medicamentos subordinados a prescripción médica no ha sido admitida por el ALI).

Todo parece indicar que el comment $k$ dirige su atención al campo de los medicamentos. En efecto, en este ámbito no es difícil encontrar productos "inevitablemente inseguros". Según lo que se ha podido leer (v. retro en el texto, p. 8), el comment $k$ presenta tres categorías de productos "inevitablemente inseguros": medicamentos que ofrecen muchos beneficios, pero son altamente riesgosos, como por ejemplo la vacuna contra la rabia; aquéllos que a causa de su alto grado de riesgo no se pueden vender sin una prescripción médica; $y$ aquellos medicamentos nuevos o en estado de experimentación.

Para comprender mejor lo que se ha señalado en torno al comment $k$ puede ser útil considerar la cuestión de si un vendedor de un producto "inevitablemente inseguro" puede llegar a ser responsable en ausencia del comment $k$. Para dar una respuesta al interrogante es preciso referirse a lo dispuesto en el comment $i$ de la sección 402A.

El comment $i$ precluye la responsabilidad en los casos en que los riesgos hayan sido conocidos según el bagaje de conocimientos que puede tener un consumidor ordinario (Prosser sostenía que el test adecuado para saber si un producto era "irrazonablemente peligroso" consistía en preguntarse si el peligro del producto iba más allá de los conocimientos de un consumidor ordinario. Cfr. J.A. Page, Generic product risks, cit., p. 863). Con base en este perfil, si un paciente sufre un daño como consecuencia de la ingesta de un medicamento riesgoso, pero, al mismo tiempo, el producto ofrece muchos beneficios y el daño resulta estando dentro de los parámetros del fin del riesgo previsto, de ello sigue que no se está frente a un producto irazonablemente peligroso.

Por tanto, si se tiene en cuenta la extensión y la flexibilidad del comment $i$, se puede conferir un contenido aún más preciso al comment $k$. En efecto, sin una previsión como la que pertenece a este último comment se podría pensar que el daño derivado de riesgos no conocibles o bien de riesgos que devienen más graves de lo que se esperaba, puede ser resarcido a la luz del régimen de la responsabilidad objetiva.

La precedente interpretación conduciría a sostener que el objetivo del comment $k$ es excluir los riesgos no conocibles ocasionados por los productos "inevitablemente inseguros" mientras que el comment i excluye los riesgos conocidos por la aplicación de la responsabilidad objetiva. Pero aun esta interpretación presenta dificultades, de hecho se debe subrayar que el comment $k$ no hace una referencia directa o expresa a los riesgos no conocibles, sino a los riesgos conocibles. Por ejemplo, menciona el caso de los riesgos que derivan de la vacuna antirrábica. Además, se puede anotar que, en relación con el caso de los nuevos medicamentos o de los medicamentos en experimentación, productos inevitablemente inseguros porque presentan riesgos no conocibles, desde el momento en que un paciente presta su consentimiento, precedido obviamente de la información pertinente, a fin de someterse a ciertas pruebas médicas, él está informado sobre las posibles consecuencias del mediamento y, por tanto, se puede afirmar que cualquier reacción entra en el ámbito de conocimiento del consumidor (v. Campbell, Civil liability for investigational drugs, II, 42, Temple L.Q. 289, 335-336 [1969]). Durante los debates en el ALI, Prosser se refiere al comment $k y$ sostiene que éste ha sido preparado para proteger "a la persona que venda un medicamento necesariamente inseguro pero de una utilidad superior a los riesgos". Nótese que está clara la referencia a un riesgo que hace 
al producto devenir necesariamente inseguro, no obstante, el conocimiento al momento en que el producto fue puesto en el mercado (cfr. J.A. Page, Generic product risks, cit., p. 868 ss.).

A diferencia del comment $k$, el comment $j$ habla específicamente de los riesgos no conocidos al momento de la puesta del producto en el mercado. Pero a decir verdad, este comment crea más confusión que claridad, y además deja sin contenido al comment $k$ (el comment $j$ prevé: "El vendedor puede razonablemente asumir que aquéllos que sufren de alergias comunes, por ejemplo, a los huevos o a las fresas, son conscientes de este hecho, y por tanto no se le exige al vendedor que les advierta sobre los riesgos". Id., p. 869). En efecto, del comment $j$ se puede deducir que si el riesgo no es reconocible, no obstante, la atención debida y, en consecuencia, el consumidor no está tampoco en grado de conocerlo, el productor no será responsable objetivamente.

Si del comment $j$ resulta que la responsabilidad del productor queda excluida en caso de riesgos medicinales no conocibles y extensivamente que tal responsabilidad queda excluida para todos los casos de "riesgos genéricos no conocibles", el comment $k$ restaría sin contenido propio, diferenciable de los otros.

Como se ha puesto en evidencia, existen diversas interpretaciones en torno al comment $k$ de la sección 402A del Restatement (Second) of Torts. Sobre todo, se constata poca claridad en la definición de un producto inevitablemente inseguro, de la cual dependerá la aplicación de la excepción prevista en el mencionado comment, es decir, la no aplicación en este caso de la responsabilidad objetiva. Todo esto no permite alcanzar una distinción entre los medicamentos que deben ser sometidos a prescripción médica y aquéllos que, en cambio, pueden circular libremente en el mercado, como en el caso de los medicamentos en estado de experimentación. Igualmente el Restatement no distingue entre los llamados riesgos conocidos y los riesgos no conocibles, y en los comentarios no aparece una posición clara que se refiera a la aplicación de la responsabilidad objetiva en uno o en ambos casos (a propósito de lo expuesto en el texto, Prosser había señalado hace más de 25 años que cualquier intento de distinción entre los medicamentos y otros productos llevaba consigo un grave riesgo. Señalaba que ahora la expansión de la responsabilidad del productor por productos alimenticios hacia cualquier producto, sugería que no se deberían hacer otras distinciones. Cfr. J.C. Kelso, Brown v. Abbott Laboratories and Strict Products Liability, cit., p. 27 ss.).

\section{Riesgos genéricos}

En los casos como el DES, que, como se ha dicho, representa el punto de partida en la ilustración que se viene desarrollando sobre el régimen de la responsabilidad del productor a la luz del derecho norteamericano, uno se encuentra frente a riesgos que no son conocibles en el momento de la puesta del producto en el mercado. En efecto, se trata de productos que tienen como característica la capacidad de crear riesgos que ponen en peligro a todo consumidor, aunque no necesariamente ocasionan efectivamente un daño.

En el derecho norteamericano tales riesgos son llamados generic produce risks o riesgos genéricos. Hay dos tipos de riesgos genéricos. Uno es entendido como design risk o riesgos que pueden ser eliminados o reducidos sólo cambiando el diseño del producto. El otro tipo de riesgos genéricos está constituido por los productos tóxicos, como es el caso del DES.

A diferencia del primer tipo de riesgos genéricos, en el cual el riesgo del producto está ínsito en éste y es necesario para realizar el objetivo para el cual fue creado (por ejemplo, el filo de un cuchillo, la velocidad de un automóvil), en los casos DES el productor no pretende crear voluntariamente el riesgo 
que este tipo de producto comporta, porque el riesgo es inherente a la función del producto. En efecto, en este último caso, la capacidad del DES de crear un cierto tipo de cáncer en las hijas de las mujeres que consumieron el medicamento no se relaciona con la eficacia del producto. En este caso, el riesgo de toxicidad es inherente a la naturaleza del producto, no está relacionado con el diseño y lamentablemente no puede ser eliminado en el estado actual de los conocimientos científicos, a menos que el producto sea retirado del mercado (en ciertos casos los productores pueden reducir los riesgos genéricos relativos a los productos tóxicos). Esto es posible si ellos proporcionan a los consumidores la adecuada información concerniente a tales riesgos. Ciertamente una adecuada información será eficaz si se trata de riesgos que son conocidos o conocibles al momento de su introducción en el mercado. En los casos DES los riesgos sobre los efectos cancerígenos del medicamento no eran conocidos en el momento en que el consumidor fue expuesto al producto (J.A. Page, Generic product risks, the case against comment $k$ and for strict tort liability, cit., p. 857 ss.).

Existen otros tantos ejemplos de riesgos genéricos pertenecientes al segundo grupo; entre éstos las reacciones alérgicas a ciertas medicinas, el riesgo de contraer un cáncer como consecuencia del humo del cigarro, el riesgo de un shock tóxico, los posibles efectos dañinos derivados del consumo de la cafeína, o del alcohol -en la hipótesis en que estas sustancias fueran un día calificadas como peligrosas.

Así como existen diversos tipos de riesgos genéricos, si bien algunos conformes a su diseño, otros inherentes a su naturaleza, se puede también encontrar una ulterior diferenciación entre los riesgos genéricos en función del grado de conocimiento de tales riesgos. Por tanto, ciertos riesgos, como el consistente en la posibilidad de contraer un cáncer como consecuencia de fumar, son bastante conocidos tanto por el productor como por el consu- midor. En cambio, existen otros riesgos genéricos, como en el caso de los efectos cancerígenos del DES, que no eran conocidos en el momento en que el consumidor fue expuesto al medicamento. $Y$ aún se puede decir que los posibles efectos dañinos de ciertos productos (como la cafeína, por citar un ejemplo), permanecen ignorados en el estado actual de los conocimientos.

Como se puede deducir de lo que se ha dicho precedentemente, el Restatement no hace una distinción entre los riesgos conocidos y los no conocidos, y ni siquiera toma una posición sobre cuáles son los riesgos que deben ser objeto de la strict liability. El comment $k$ que indica cuándo un producto es inevitablemente peligroso no ofrece una indicación clara que permita aplicar a determinados casos la regla de la exclusión a la responsabilidad objetiva a que hace referencia.

El trend de la jurisprudencia norteamericana en relación con la aplicación de la strict liability a los casos de productos tóxicos es en sentido negativo. Esta tendencia no hace más que reflejar aquélla más consolidada según la cual la responsabilidad objetiva viene limitada sólo a los casos de defectos de fabricación, es decir, aquéllos en que el producto no resulta ser tal como lo entendía el productor (D. Leebron, Introduction to products liability origins, issues and trends. Annual Survey of American Law, N.Y., 1993, p. 401). En efecto, los partidarios de esta tendencia aplican el negligence test en los casos de defecto de proyecto (v. Birnbaum, Unmasking the test for design defect: From negligence to warranty to strict liability to negligence, 33 Vand. L. Rev. 593 (1980).

\section{Defecto de proyecto}

Los casos de responsabilidad del productor de fármacos ponen el problema nada sencillo de la individualización de un defecto de proyecto.

En efecto, cuando en 1965 fue aprobado el texto definitivo del Restatement (Second) of Torts, según 
el cual la así llamada strict liability se aplica a cualquier producto, esto es, sin distinguir si se trata de un producto alimenticio o no (porque inicialmente a este tipo de producto venía limitada la propuesta inicial del Restatement of Torts) los comentaristas no habrían imaginado las consecuencias que habría determinado el hecho de aplicar la regla sobre la responsabilidad objetiva a los casos de daños derivados de un defecto de proyecto. Si bien entonces ya se conocía el concepto de proyecto (cfr. Noel, Manufacturer's Negligence of Design or Directions for Use of a Product, 71 Yale L.J. 816 [1962]), los artífices de la sección 402A consideraron innecesario hacer una adecuación de las reglas de responsabilidad objetiva para precisar cómo y cuándo estas reglas se debían aplicar a un caso de defecto de proyecto.

En efecto, el impacto más significativo de la introducción de una regla general de responsabilidad objetiva por productos defectuosos se ha producido en el ámbito de los juicios en materia de defectos de proyecto. Hay confusión e incertidumbre sobre la definición y la determinación en juicio de un defecto de proyecto. Los términos "defectuoso" e "irrazonablemente peligroso" son decisivos en la formulación de la sección 402A del Restatement of Torts. En los años sucesivos a la emisión de dicho Restatement los comentaristas han encontrado inadecuada tal formulación sobre la responsabilidad objetiva y se han empeñado en tratar de proponer un test para la determinación de la responsabilidad objetiva en los juicios relativos a los defectos de proyecto.

Aunque el tema de los defectos de proyecto no ha sido considerado como un problema durante las fases de elaboración de la sección 402A del Restatement, algunos casos de riesgos genéricos han sido tal vez objeto de preocupación por parte de los comentaristas del Restatement y por parte de los miembros del American Law Institute (en efecto, los autores del Restatement eran conscientes de las controversias que habrían surgido en la determinación del nexo de causalidad entre fumar cigarrillos y el cáncer, como entre la ingesta de ciertos fármacos y los daños que de ello derivan". Por tanto, se plantearon el problema de si es justo someter la industria del tabaco y la farmacéutica a la responsabilidad objetiva. Estos productos se vinculan con el comment $\mathrm{k}$ de la sección $402 \mathrm{~A}$ del Restatement (Second) of Torts.

Como bien sabemos la responsabilidad objetiva del productor encuentra su fundamento en el carácter defectuoso del producto. Por ende, a diferencia de la negligence en que se tiene en cuenta los conocimientos existentes al momento de la realización de la conducta, en la responsabilidad objetiva importa el producto en sí mismo. Por otra parte, no obstante el concepto de defecto no sea variable en relación con el tiempo en el ámbito de la responsabilidad objetiva, en cambio, el hecho tiempo plantea problemas de determinación de la misma (v. Wade, John W., On the effect in product liability of knowledge unavailable prior to marketing, en N.Y. Law Rev., New Jersey, 1983, p. 739 ss.). Ciertamente, se puede pensar en casos de riesgos no conocidos al momento de la puesta del producto en el mercado.

El problema de la definición del concepto de "defecto" se complica porque la misma terminología es utilizada para hacer referencia a dos nociones muy diversas entre sí.

En verdad, el término "defecto" se refiere de un lado al llamado defecto de fabricación en el cual el significado de defecto no crea particulares dificultades en términos de reconocibilidad, dado que el producto es evaluado a la luz de los parámetros señalados por los éstandares de producción del propio fabricante,presentes también en los otros productos pertenecientes a la misma línea de producción. Por otro lado, el término defecto se refiere al llamado defecto de proyecto y por esto se entiende un proyecto que tecnológica y económicamente se podía considerar hecho seguro, si hubiera sido eliminado o bien reducido el 
peligro de daño. Si luego el producto se presenta muy peligroso, no debe ni siquiera ser puesto en circulación. Y, a los efectos de determinar el nivel de peligrosidad del producto más allá del cual éste no debe ser puesto en el mercado, se han propuesto en doctrina algunos tests que las Cortes han tenido en cuenta en la evaluación de la defectuosidad.

En el caso de un defecto de proyecto, la víctima debe demostrar que el proyecto del producto crea riesgos irrazonables, por tanto, la atención se dirige no tanto sobre el producto en sí como sobre la elección hecha por el productor. Por ello la aplicación en este caso de la expresión "condición defectuosa en modo irrazonablemente peligroso", prevista en la sección 402A del Restatement (Second) of Torts, crea grandes dificultades en la evaluación del carácter defectuoso del producto.

De hecho la responsabilidad objetiva parece ser eficaz frente a los defectos de fabricación en los cuales el test para determinar el carácter defectuoso de un producto es realizado sobre la base de los éstandares de fabricación del mismo productor y de la industria. No es lo mismo cuando se trata de aplicar el mismo régimen a los casos de defectos de proyecto por las dificultades que plantea precisamente el hecho de identificar el defecto.

Desde el caso Greenman, cuya decisión da vía en los Estados Unidos a la orientación de la jurisprudencia que se concreta en la afirmación de la strict liability, y desde la aprobación de la sección 402A del Restatement, las cortes norteamericanas han puesto gran empeño en la elaboración de los éstandares que permitan resolver los casos de defectos de proyecto (v. S. Birnbaum, Unmasking the test for design defect..., cit., p. 643 ss.).

El acercamiento de la jurisprudencia no ha sido del todo uniforme en su intento de proporcionar una definición y una evaluación del defecto de proyecto. Como se verá más adelante tal variabilidad queda evidenciada en las diversas decisiones que aplican éstandares diferentes de evaluación.

Un modo para reducir la peligrosidad de un producto consiste en proveer al consumidor una adecuada información. Dicha información es parte integrante de la proyecto del producto $y$, por ende, debe ser considerada como un elemento determinante de la seguridad de un producto. Por ende, aun la carencia de información a menudo es entendida como un defecto a los efectos de la accionabilidad, $y$ en realidad, los casos de falta de información deben ser considerados como pertenecientes a los casos de defecto de proyecto $(\mathrm{v}$. Noel, Products Defective because of Inadequate Directions and Warnings, 23 Sw. L.J. 256 (1996).

Se dijo antes que el elemento tiempo plantea delicados problemas cuando se está en el ámbito de la responsabilidad objetiva, en el cual teóricamente no debería importar más que el producto defectuosos y su conexión causal con el daño. Habiendo precisado esto, resulta que la mayor parte de los problemas que suscita el factor tiempo toca el defecto de proyecto.

Ya se ha puesto de relieve y parece que se puede considerar que son tantos los casos en que la peligrosidad de un producto no es verificable, según el estado de la ciencia al momento de la puesta en circulación, si no después de algún tiempo; de hecho el desarrollo de la ciencia y de la técnica juega un rol fundamental en la determinabilidad del defecto.

Nuestro examen concierne al caso de los riesgos genéricos no conocidos en el momento de la puesta del producto en el mercado en relación con los cuales es particularmente difícil, si no imposible, individualizar la fuente del daño. Desde esta perspectiva es interesante verificar cómo la jurisprudencia norteamericana se ha pronunciado y cuáles reglas ha debido crear para afrontar el problema de la causalidad, con ocasión de los casos DES. 


\section{Casos de responsabilidad por productos farmacéuticos resueltos por las cortes norteamericanas}

El argumento que aquí se trata atiene al uso del fármaco DES, una sustancia que entre los años 1947 y 1971 se había prescrito en los Estados Unidos a muchos pacientes para prevenir abortos espontáneos. Pero, los efectos posteriores al uso del fármaco mencionado fueron de insospechable e insospechada gravedad. En efecto, resulta que muchos años después de la ingesta de tal sustancia por parte de las madres nacieron hijas que luego sufrieron cáncer en el cuello cervical.

Como ya se ha dicho, los efectos dañinos del DES fueron descubiertos mucho tiempo después de que el fármaco fue puesto en circulación con un relevante número de víctimas. El transcurrir del tiempo entre la puesta en circulación del DES y el descubrimiento del daño hizo problemática la individualización de los fabricantes del producto que habían ocasionado el daño.

Debido a lo anterior, las vícitmas se organizaron en class actions. En algunos casos, el resultado del juicio les fue favorable, mientras en otros, los jueces no concedieron el resarcimiento requerido.

Ya que los hechos sobre los que se basan las demandas de resarcimiento por el daño causado por el DES son los mismos en las diversas causas instauradas por víctimas diversas, se trata genéricamente de ellos y en seguida se hace referencia a aquellos casos en que fue concedido el resarcimiento con base en las teorías que la jurisprudencia norteamericana ha debido crear para proteger a las vícitimas de una dificultosa prueba del nexo causal.

Los hechos de los llamados DES cases pueden ser resumidos del modo siguiente:

Entre 1941 y 1971, las casas farmacéuticas habían participado en un negocio consistente en la producción, difusión y comercialización de una sustancia de nombre diethylsilbesterol (DES), un fármaco compuesto de una hormona femenina. El fármaco había sido suministrado a las madres de las víctimas demandantes con el objetivo de prevenir el aborto espontáneo. En 1947 la Food and Drug Administration autorizó la comercialización del DES como un abortivo, pero sólo a título de experimentación y con la condición de que tal comercialización estuviera precedida por una adecuada información.

El DES puede ocasionar cáncer a la vagina y al cuello cervical en la prole expuesta al fármaco durante el embarazo de las mujeres que tomaron el medicamento. El tipo de cáncer que presentan las hijas es conocido como "adenocarcinoma", y los síntomas aparecen después de un periodo de latencia de diez o doce años. El DES también puede ocasionar otros tipos de anomalías a los órganos genitales femeninos. A menudo dichos síntomas no aparecen en el individuo que ha ingerido la sustancia tóxica.

En 1971 la FDA dispuso detener la comercialización del DES y advertir a los científicos y a los consumidores acerca de la necesidad de no utilizar tal fármaco.

Las víctimas sostenían que los demandados conocían o debían conocer que la sustancia comercializada por ellos producía efectos cancerígenos. No obstante, los demandados no retiraron del mercado el mencionado fármaco. Las demandantes afirmaban, además, que los demandados no habían experimentado el fármaco antes de introducirlo en el mercado, sino que habían confiado en los tests realizados por otros. Todo esto contribuía a hacer comprender que el fármaco no era seguro ni eficaz en la prevención del aborto.

La dificultad más relevante que tuvieron que afrontar en juicio las víctimas del DES tenía que ver con la imposibilidad de establecer un nexo de vinculación entre el fármaco ingerido por sus madres hace 
un cuarto de siglo y la específica casa comercial. Pasada una generación no quedaba prueba de que pudiera conducir a la identificación del productor cuyo fármaco ocasionó el daño.

Por tanto, de los casos DES afloran dos cuestiones fundamentales: la que se refiere a la difícil identificación del productos a quien imputar los daños y la relativa a los principio sobre la base de los cuales las sentencias de las Cortes norteamericanas fundaron sus decisiones. Se verá en seguida cómo las Cortes norteamericanas afrontaron el problema de la causalidad.

Un caso es el caso Sindell v. Annott Labs., 26 Cal. 3d 588, 610-13, 607 P. 2d 924, 936-38, 163 CaL Rptr. $132,144-146$.

Este caso se ha hecho conocido en los Estados Unidos porque por primera vez los jueces han adoptado el criterio de la Cuota de Mercado (Market share) a los efectos de la atribución de la responsabilidad a los productores que habían puesto en circulación el DES.

La Corte de primer grado resuelve las cuestiones preliminares a favor de los demandados en el sentido que éstos no podían ser considerados objetivamente responsables por el defecto del DES si no por no haber advertido los efectos dañinos, conocidos o conocibles, del fármaco; así también la Corte niega la posibilidad de la responsabilidad por fraude o por violación de garantías en un procedimiento basado sobre la teoría de la "market share liability". La sentencia de la Corte precisó que en caso de éxito de la demandante los demandados no serían considerados responsables en sólido por el total del resarcimiento, sino que cada uno lo sería en proporción a la respectiva cuota de mercado del DES.

Las Cortes Superiores de Los Angeles rechazan las demandas y, por ello, las víctimas presentan apelación. El juez de la Corte Suprema, Mosk, afirma que no obstante no sea posible identificar al productor del fármaco DES, la víctima puede sostener que los productores del fármaco derivado de una génerica fórmula química son responsables por los daños ocasionados. A este fin la vícitma debe probar que los demandados produjeron un porcentaje sustancial de la sustancia en cuestión, resultando así que cada productor es responsable por la cuota de participación en el mercado, a menos que demuestre que él no ha sido el productor del fármaco que ha ocasionado los daños.

La motivación de la sentencia de la Corte Suprema de California comienza poniendo de relieve como regla general aquella que establece que: "la atribución de responsabilidad depende de la prueba a cargo de la víctima, de que los daños sufridos fueron causados por un hecho del demandado o por un instrumento que depende del control de este último".

No obstante, existen excepciones a la regla, en la demanda la víctima pone con base en sus pretensiones algunas teorías que pueden llevar a considerar a los demandados responsables por los daños, aunque la víctima no pueda probar el nombre del fabricante que ha producido el DES ingerido por la madre. La primera de estas teorías, clásicamente ilustrada a través Summers $v$. Tice (1948) 33 Cal.2d. 80, 199 P.2d 1, atribuye a los demandados la carga de la prueba de la causalidad sobre la base de ciertas circunstancias. El segundo fundamento de la responsabilidad que la parte demandante quiere imputar a los demandados se refiere a las acciones concurrentes a fin de ocasionar los daños a la víctima. Y hay aún una tercera y nueva aproximación al problema. Se trata de la llamada enterprise liability, que se prefiere definir industry-wide liability, con la que es posible obviar la necesidad de identificar al productor cuyo producto ha sido la causa del daño. Debemos concluir que todas estas teorías no alcanzan para sostener fundadamente la responsabilidad de los demandados sobre la base de los hechos citados 
por la vícitima. No obstante ello, se puede proponer una cuarta teoría que resulta ser una extensión de la doctrina contenida en Summers.

La primera argumentación de la víctima señala que si una parte no puede identificar entre dos o más demandados a aquél que ha ocasionado el daño, la carga de la prueba se traslada sobre los demandados quienes deben demostrar no ser responsables. Este principio es conocido como la teoría de la responsabilidad alternativa (alternative liability).

El conocido caso Summers $v$. Tice es un ejemplo de aquella regla. En Summers la víctima sufre un daño cuando dos cazadores disparan en la misma dirección. No es posible determinar cuál de los dos cazadores disparó ocasionando una grave lesión en el ojo de la víctima, pero los demandados fueron considerados responsables solidarios por el entero daño. Nosotros razonamos en el sentido que ambos cazadores han sido negligentes hacia la víctima y hubiera sido injusto pedir a la víctima individualizar al demandado responsable, porque si uno de ellos podía excluir su responsabilidad en el mismo modo podía hacerlo el otro demandado y la vícitima hubiera quedado sin tutela. Frente a estas circunstancias, se sostuvo que la carga de la prueba se traslada hacia los demandados... Se dijo entonces que en estas circunstancias es más fácil imponer al demandado la carga de la prueba de no haber ocasionado el daño o probar que lo ha ocasionado otro demandado.

En el caso Summers vs. Tice nos hemos referido al caso Ybarra v. Spangard (19944) 25 Cal.2d 486, 154 P.2d 687. En este caso un paciente fue dañado durante una intervención quirúrgica. La víctima pidió el resarcimiento contra los médicos que habían participado en la intervención. Nosotros hemos considerado que hubiera sido irrazonable pedir al paciente que identifique al dañante ya que al momento del daño el paciente estaba en estado de inconciencia... Por tanto, a la luz de la doctrina del res in ipsa loquitur se afirmó una presunción de culpa de los demandados.

La regla sancionada en el caso Summers vs. Tice ha sido recibida en el Restatement of Torts (Rest. 2d Torts, s 433B, subsec. [3]).

Los demandados consideran que los principios del caso Summer no son aplicables en el siguiente caso. Ellos sostienen que el fundamento para trasladar la carga de la prueba en Summers e Ybarra es que los demandados deben tener un bagaje de información más amplio con respecto a la vícitma en relación con la causa de los daños, cosa que no se verifica en el caso en examen.

La víctima no afirma que los demandados se encuentren en una posición mejor con respecto a ella para identificar al productor del fármaco tomado por la madre..., pero pone de relieve que Summers no impone esto como requisito para el traslado de la carga de la prueba. Sobre este punto creemos que la víctima está en lo cierto.

En este caso como en Summers, las circunstancias en que se produce el daño parecen hacer imposible a la víctima o a los demandados la identificación del productor del fármaco tomado por la madre de la víctima...

...Mientras se ha dicho que los demandados han construido un producto defectuoso con efectos que se manifiestan en el tiempo, la dificultad o imposibilidad de identificar al responsable es atribuida fundamentalmente más al transcurso del tiempo que a la conducta negligente consistente en la falta de información adecuada...

Es importante señalar que, para la víctima y para los demandados no es fácil individualizar al productor preciso del fármaco ingerido por la madre de la víctima, mientras al productor demandado tal vez es posible probar que la sustancia que ocasionó el daño no ha sido producida por él... 
Por ende, arribamos a la conclusión de que el hecho de que los demandados no tengan una amplia posibilidad de información que pueda determinar la identificación del productor del DES que ocasionó el daño a la víctima no constituye un obstáculo para la aplicación de la regla del caso Summers...

...Existe una diferencia importante entre el caso Summers y el presente caso. En el primero, todas las partes que fueron o pudieron ser responsables del daño ocasionado a la víctima fueron demandadas en juicio. En el presente caso, en cambio, hay 200 empresas productoras de fármacos que produjeron el DES, y cualquiera de ellas puede ser responsable de la producción de la sustancia que ocasionó el daño.

Los demandados consideran que mientras en Summers había un 50\% de probabilidad de que uno de los demandados fuera responsable del daño, en el presente caso, en cambio, una de las 200 empresas productoras del DES podía ser la que produjo la sustancia que dañó a la víctima. Por ello no hay motivo razonable para deducir que cualquiera de los demandados haya podido ocasionar los daños.

Estas argumentaciones son muy persuasivas si se mide la probabilidad de que cualquier demandado pudo haber proporcionado la sustancia que ocasionó los daños en función del número de los posibles dañantes. En este contexto, la posibilidad de que uno de los cinco llamados en causa haya proporcionado la sustancia a la madre de la víctima deviene muy remota $y$, por ende, resulta injusto pedir para cada demandado la exoneración de la responsabilidad... Mientras lo que proponemos infra es una adecuación de la regla sancionada en el caso Summers que podrá superar estas dificultades...

El segundo principio que afirma la víctima es el llamado "concierto de acciones" ("concert of actions" theory)...

Nuestra opinión es que las consideraciones de la demandante que sostienen su pretensión son insuficientes. La imputación de una acción en concurso reside en el hecho de que los demandados no han sometido el fármaco a los exámenes correspondientes, que no han procurado la información sobre los peligros del fármaco, que han confiado en los tests realizados por otros y que han aprovechado las ventajas de la publicidad y comercialización realizadas por otros productores de dicho medicamento. Estos asertos no constituyen el fundamento de la imputación de un acuerdo implícito o bien de un programa común entre los demandados para no realizar tests y para no procurar la información necesaria...

Lo que la protesta de la víctima parece atribuir a los demandados es su comportamiento paralelo al confiar en los tests y en los métodos publicitarios realizados por los otros. Pero tal comportamento describe una usanza común en la industria: un productor se vale de la experiencia y métodos de los otros que producen los mismos o similares productos. Una aplicación de la teoría concert of actions en el presente caso ensancharía la extensión de la doctrina más allá de su fin y haría responsable a cada productor por los productos defectuosos de una entera industria.

La tercera teoría citada por la víctima es la de la "industry-wide liability"... Esta teoría fue sugerida en el caso Hall vs. E. L Du Pont de Nemours \& Co., Inc. (E.DN.Y. 1972) 345 F. Supp. 353. En aquel caso las víctimas eran trece niños dañados por los llamados dynamite blasting caps (proyectiles). El caso tuvo lugar en diez estados diversos de los Estados Unidos entre 1955 y 1959. Los demandados eran seis productores de blasting caps. Todos juntos representaban la entera industria de dicho producto en los Estados Unidos, así como su asociación de comercialización.... El fundamento de la protesta era que la práctica industrial de no procurar informaciones en cada producto y de no adoptar las oportunas medidas de seguridad creaban un riesgo irrazonable... La protesta no identifica a un productor en particular como fuente del daño. 
El razonamiento de la corte era el siguiente: existía prueba del hecho de que los demandados, obrando independientemente, habían conformado una industry-wide standard en relación con las características de seguridad del material explosivo, que habían delegado algunas responsabilidades sobre la investigación de seguridad y sobre el diseño... a su asociación, y había una industry-wide colaboración en la fabricación y en el diseño del mencionado material explosivo. Frente a estas circunstancias, la prueba llevaba a la conclusión de que todos los demandados habían controlado el riesgo, por tanto, si las víctimas demostraron según cuanto se ha deducido de las graves evidencias que el material explosivo estuvo en posesión de uno de los demandados, la prueba de la causalidad viene a trasladarse a todos los demandados. La corte puso de relieve que esta teoría de la responsabilidad es aplicable a las industrias que tienen un número reducido de productores... y que sería injusto aplicarla a una industria compuesta por un número indefinido de pequeños productores.

No consideramos aplicable aquella teoría al presente caso. Hay al menos 200 productores del DES. Además, en Hall se llega a la conclusión de que todos los demandados han controlado el riesgo desde el momento en que han delegado responsabilidad sobre la seguridad del producto a su asociación de comercialización. En el presente caso no existe tal afirmación por parte de la víctima...

Como se puede deducir de la motivación de la sentencia en examen, según los jueces, ninguna de las teorías citadas por la actora resultaba aplicable en el presente caso, en el sentido de que tales teorías no concederían a la víctima el resarcimiento de los daños sufridos. No obstante ello, los jueces de la corte californiana consideraron que existían sólidos fundamentos en apoyo de la tesis de la víctima.

Estando a las circunstancias del caso, los jueces han puesto de relieve que así como el tradicional estándar de la negligence se reveló insuficiente para regular los deberes del productor hacia los consumidores, se debe reconocer necesario una adecuación de las reglas de causalidad y las de responsabilidad frente a las circunstancias presentes.

Sobre la parte decisiva de la sentencia dada en el caso Sindell, la motivación de la corte californiana señala:

La razón más convincente a favor de la pretensión de la víctima es la señalada en el caso Summers: entre una víctima inocente y algunos demandados culpables, estos últimos deben soportar el costo del daño. En este caso, como en Summers, la víctima no está en culpa por el hecho de no haber logrado procurar la prueba de la causalidad, y si bien la ausencia de tal prueba no sea tampoco imputable a los demandados, ello no significa que su comportamiento en la comercialización del fármaco cuyos efectos han estado latentes por tantos años no haya jugado un rol determinante en la dificultad de propoprcionar la prueba.

El productor se encuentra en una posición mejor para descubrir y para protegerse contra los defectos de sus productos así como para informar sobre los efectos dañinos; la imputación de una responsabilidad por los defectos y por la falta de información sobre los efectos dañinos determina, por tanto, un incentivo a los fines de la seguridad de la producción (Cronin v. J.B.E. Olson Corp. [1972] 8 Cal.3d 121, 129, 104 Cal. Rptr. 433, 501 P.2d 1153; Beech Aircraft Corp. v. Superior Court [1976] 61 Cal. App. 3d 501, 522’523, 132 Cal. Rptr. 54 I.).

En los casos en que, como en éste, todos los demandados han producido el fármaco según una fórmula idéntica y no es, empero, posible identificar al productor del DES que ha ocasionado el daño, allí está garantizado una adecuación de la regla sancionada en el caso Summers... La ratio del caso Summers resulta inadecuada para hacer 
trasladar la carga de la prueba de la causalidad a los demandados, porque si nosotros medimos la probabilidad de que cada fabricante haya proporcionado el producto que ocasionó el daño en función del número de productores del DES, existe la posibilidad de que ninguno de los cinco demandados del presente caso haya producido la sustancia lesiva, de tal manera que el responsable no llamado en causa termine exento de responsabilidad.

Pero nosotros afrontamos la cuestión de la causalidad desde una óptica diversa: consideramos razonable evaluar la probabilidad de que cualquier demandado haya proporcionado el producto que presumiblemente ha dañado a la víctima en un porcentaje que representa las ventas de DES destinadas a la prevención del aborto realizadas por cada productor en relación con la entera producción del fármaco vendido por todos los productores con el objetivo señalado.

Si la víctima logra demandar en juicio a los productores de una cierta notable proporción del DES sobre el mercado, entonces viene reducida la injusticia consistente en el hecho de trasladar la carga de la prueba sobre los demandados; ellos deben demostrar que no han producido la sustancia que ha ocasionado el daño... Consideramos que sólo se considera en juicio un cierto porcentaje del DES introducido en el mercado.

La presencia de una considerable participación en el relativo mercado ofrece un instrumento práctico para distribuir los daños entre los demandados. Cada demandado será considerado responsable en proporción a su participación en el mercado a menos que demuestre que él no ha producido la sustancia que ha ocasionado el daño... El productor demandado en juicio puede luego llamar en causa a los otros productores del DES que pueden haberlo introducido en el mercado.

Bajo este perfil, la responsabilidad de cada productor viene calculada de manera aproximativa en función de los daños ocasionados por sus productos. Es inevitable que haya alguna discrepancia en la relación entre la cuota del mercado y la responsabilidad... Resulta casi imposible, con el trascurso del tiempo determinar exactamente la cuota de mercado... Como se dijo en Summers, en relación con la responsabilidad de los dañantes, aun donde no fuera posible hacer una división correcta, el "juez debe hacer lo mejor posible".

...Sobre la base de la regla que adoptamos, la responsabilidad de cada productor por un daño sería aproximadamente equivalente a los daños causados por el DES que él ha producido.

Los casos DES a que nos referimos en seguida presentan el mismo problema de fondo, esto es, la imposibilidad de encontrar al responsable del daño. Pero, ya que los hechos son en sustancia los mismos del caso Sindell, aun siendo las partes diversas sólo se citará algunos pasajes fundamentales de las sentencias que se refieren a la solución dada en cada caso.

En el caso Ferrigno v. Eli Lilly \& Co., 175 N.J. Super. 551, 567-69, 420 A 2d 1305, 1314-16 (Law Div. 1980), la Corte de New Jersey al examinar el caso ha señalado que los aspectos fundamentales para tener presente en la solución del caso son los siguientes:

(1) Aunque las víctimas no podían determinar cuáles de los demandados habían producido, distribuido y vendido el DES, era oportuno trasladar la carga de la prueba de la inculpabilidad a la exoneración; (2) Los productores que no lograban exonerarse devenían responsables según su participación en el mercado; (3) En los casos de prescripción de fármacos, la responsabilidad objetiva se aplica siempre que el fármaco no se haya podido presentar razonablemente útil al momento de la producción, o bien donde, no obstante su eficacia aparente, ha sido reconocido científicamente que era previsible que el riesgo superase a los beneficios; (4) Se ha 
pedido a las vícitimas probar que sus madres consumieron el fármaco, que esta sustancia ocasiona un cáncer en la prole de sexo femenino... y que el cáncer y otras enfermedades de las víctimas han sido ocasionadas por la ingesta del medicamento por parte de sus madres; (5) Cuando una de las hijas no pueda identificar la empresa productora del fármaco tomado por la madre, ella debe de todos modos demostrar que cada demandado ha producido o bien comercializado dicho fármaco, el cual ha sido vendido en el Estado antes que la madre lo ingiriese $y$ que ha sido producido para prevenir el aborto espontáneo.

La corte de New Jersey ha aplicado una de las teorías que han sido analizadas en el caso Sindell. En efecto, este caso fue resuelto a favor de las víctimas con base en la teoría de la alternative liability.

Esta Corte señaló que el problema de la identificación del responsable se articula en dos partes: (a) la imposibilidad de identificar al verdadero responsable del daño y (b) la posibilidad para quien no ha sido identificado como responsable de no encontrarse frente al tribunal.

La Corte dio una solución a tal problema aplicando los mismos principios que ya se habían aplicado en un caso precedente.

En Anderson vs. Somberg (67 N.J. 291, 338 A.2d 1 (1975) la víctima había sufrido un daño durante una intervención quirúrgica a la espalda como consecuencia de la rotura de un instrumento que se había quedado dentro de la herida.

La víctima, que al momento de la intervención no estaba consciente de lo que acaecía, no estaba en la capacidad de identificar al dañante y podía decir sólo que el culpable era una persona que de cualquier modo había tenido contacto con el instrumento.

No obstante ello, sea la opinión mayoritaria, sea la opinión discordante, se encontraron de acuerdo al considerar oportuna la inversión de la carga de la prueba en las circunstancias en que una víctima, sin culpa, no está en grado de identificar al dañante, aunque sólo puede indicar que se trata de un miembro del grupo... De este modo, el demandado tiene la obligación de demostrar que no ha sido él el responsable del daño. No es, por tanto, la víctima quien debe probar la culpa del productor, sino este último quien debe probar la falta de responsabilidad.

...La opinión contraria ha reconocido que la pretensión de la víctima no debe ser rechazada sólo por la posibilidad de que el responsable no esté frente a los tribunales... y considera que la pretensión de la víctima sobrevive ante cualquier evento.

En el caso Ferrigno todos los demandados son presumiblemente responsables. La sentencia del New Jersey señaló que si las afirmaciones de la víctima son verdaderas, entonces ninguno de los demandados puede ser inocente. Las víctimas afirmaban que los demandados producían un fármaco que no ofrecía seguridad y que debían saber que era inseguro.

En el estado de New Jersey se ha difundido una práctica a favor del resarcimiento de las víctimas inocentes que no pueden ser resarcidas por otra vía, porque no están en grado de identificar la causa de los daños.

La Corte de New Jersey consideró que la cuestión de la identificación del responsable puede ser resuelta siguiendo el precedente establecido en el caso Anderson vs. Somberg. Señaló al mismo tiempo que las teorías de la enterprise liability y de la market share liability, citadas por las víctimas, no son útiles en el caso. En lo que respecta a la teoría acogida en la sentencia, la Corte señaló:

Según la doctrina de la alternative liability que es aplicable en estos casos, existen diversos modos en que el demandado puede exonerarse. Proba- 
blemente el mejor modo es el de identificar al verdadero productor.

...El demandado puede también probar nunca haber producido ni vendido el tipo específico de fármaco de que trata el presente caso... Puede probar que no ha producido el DES si no después del nacimiento de la víctima. Puede probar que nunca ha producido ni comercializado un estrógeno sintético con el objetivo de prevenir el aborto espontáneo. Puede probar que ninguno de los estrógenos sintéticos que ha producido o bien comercializado pudo alcanzar el lugar donde la madre de la víctima compró el fármaco...

...Aquellos demandados que no están en capacidad de exonerarse de la responsabilidad no quedan sin tutela. Si son más de uno aquéllos que no logra exonerarse de la responsabilidad, ellos serán considerados responsables solidarios...

Decidida la aplicación de la alternative liability, la Corte se puso el problema de cómo distribuir la responsabilidad entre los demandados. La culpa en el presente caso consistía en el hecho de haber producido el DES para la prevención del aborto espontáneo. Por ende, entre los demandados que resultaban responsables existía una sola diferencia, esto es, que uno de ellos pudiera haber introducido al mercado una mayor cantidad del fármaco, creando, en consecuencia, mayores probabilidades de que fuese suyo el producto que ocasionó el daño.

La Corte de New Jersey precisó que el problema de que trata el parágrafo precedente ya había sido examinado en el caso Sindell en el que se determinó que cada demandado debe ser considerado responsable según la prueba de mercado. En efecto, el caso Sindell había creado una nueva teoría de responsabilidad conocida como la market share liability. Pero en el caso Ferrigno esta teoría serviría para determinar la proporción en el mercado de cada demandado considerado responsable según la teoría de la alternative liability.
En el caso Bichler v. Elli Lilly \& Co., 55 N.Y. 2d 571, 584-85, 436 N.E. $2 d$ 182, 188-89, 450 N.Y.S. $2 d$ 776, 782-83 (1982) Joyce Bichler es una víctima del DES ingerido por la madre en estado de preñez en 1953. A la edad de diecisiete años la víctima presenta un cuadro de cáncer al cuello uterino. En 1974 pide el resarcimiento a la Elli Lilly \& Co. por los daños sufridos como consecuencia de una intervención quirúrgica necesaria para la extracción de los órganos reproductivos y de más de la mitad de la vagina. De dicha intervención derivó la imposibilidad para la víctima de tener hijos y de tener relaciones sexuales normales.

La Corte de Apelación de New York consideró como fundamento de su juicio la teoría de la concert of action y se pronunció de la siguiente forma:

\footnotetext{
Aquéllos que al ejecutar un programa común o bien un proyecto para la comisión de un acto dañino, son parte activa del mismo, o bien hayan prestado su colaboración o hayan involucrado a otros sujetos, o bien aquéllos que ayudan o estimulan al dañante, o bien apoyan y utilizan su hecho para obtener un beneficio, son igualmente responsables con este... Restatement, Torts 2d, s 876.
}

Una víctima puede accionar contra cualquiera que haya actuado según la teoría de la concert of action...

La Corte precisó que para encontrar al demandado responsable según la teoría de la concert of action era indispensable que se probase que: (1) Elli Lilly Co. y las otras empresas productoras del DES tenían una sola intención o un acuerdo para actuar todos juntos a efectos de obtener en el año 1947 la aprobación de la comercialización del fármaco preventivo del aborto; (2) uno de los componentes de este grupo había producido el DES ingerido por la madre de la víctima; (3) el demandado junto con los otros componentes del grupo habían asistido al verdadero productor del fármaco y el daño no se habría producido sin su asistencia; y (4) el 
demandado había querido prestar su asistencia al productor del fármaco que ocasionó el daño, o bien el demandado era consciente del comportamiento incorrecto del productor.

De este modo, la Corte había delineado los presuspuestos para individualizar al responsable de acuerdo con la teoría de la concert of action. Como se puede notar, dicha teoría podía encontrar verificación de dos modos: por un lado, en una acción común previo acuerdo de los productores para poner en el comercio el DES para la prevención del aborto espontáneo; por otro lado, en una asistencia recíproca para no someter el DES a prueba antes de ponerlo en circulación en el mercado. Esta última conducta sería una forma de estímulo para los otros productores para comportarse del mismo modo.

\section{LA RESPUESTA DE LAS CORTES NORTEAMERICANAS AL PROBLEMA DE LA CAUSALIDAD EN LOS DAÑOS POR PRODUCTO}

Los pasajes de las sentencias transcritos en los párrafos precedentes ponen en evidencia la orientación prevaleciente de la jurisprudencia norteamericana al preferir a la víctima inocente imposibilitada de demostrar puntualmente el nexo de causalidad bajo el presupuesto de que es mejor hacer responder del perjuicio a un demandado que no ha contribuido a la producción del daño específico sufrido por la víctima antes que liberar de responsabilidad a aquél que ha ocasionado el daño (R.W. Wright, "Causation in Tort LaW", en 73 Cal. L. Rev., 1985, p. 1818).

En efecto, de las motivaciones de las sentencia emergen teorías como la market share liability, la alternative liability o bien la teoría de la concert of action, concebidas para satisfacer a la víctima por Ios daños ocasionados por sujeto no identificable con certeza.

Como se observa en las sentencias tomadas en consideración, los jueces, obligados según las leyes procesales norteamericanas por resolver los problemas de la constitución de una relación procesal válida, desarrollan teorías que permiten atribuir responsabilidad a un presunto responsable del daño. Aquellas teorías tratan de dispensar a la víctima de la carga casi imposible de probar el nexo de causalidad entre el daño y el hecho del dañante, esto es, el productor del fármaco DES.

Por tanto, según la solución de las Cortes norteamericanas con respecto a los casos DES, la víctima se puede considerar relevada de la carga de individualizar la específica fuente que ha causado el daño.

La respuesta proporcionada por estas teorías al problema de la causalidad no tiene en cuenta las eventuales y diversas contribuciones causales aportadas por los productores individuales en la indagación del hecho dañino.

De este modo queda superada la concepción tradicional del nexo de causalidad como presencia de una razonable vinculación (gobernada, al mismo tiempo, por razones fenomenológicas y por aserciones científico-jurídicas) entre una determinada causa y un determinado efecto. En lugar de aquella concepción se optó por la adopción de un criterio probabilístico del nexo de causalidad según el cual, a efectos técnicos y jurídicos, con base en un cálculo de probabilidades, si un elemento puede ser idóneo para ocasionar el daño, entonces también una serie infinita de elementos puede asumir la cualidad de causa idónea para la producción de un efecto válido (cfr. Ponzanelli, Il caso Brown e il diritto italiano della responsabilità civile del produttore, en Foro it., IV, 1989, C. 128; en la doctrina norteamericana cfr. Robinson, Probabilistic Causation and Compensation for Tortious Risk, en $14 \mathrm{~J}$. Legal Studies, 1985, p. 779; Estep, Radiation Injuries and Statistics: The Need for a New Approach, en 61 Mich. L. Rev., 1964, p. 851).

Se entiende que en los casos como los atinentes al DES, el requisito de la causalidad, si no ignora- 
do, es tratado de manera tal que es como si no existiese. Se habla a propósito de una "relajación de la causalidad" (R.W. Wright, cit., p. 174 1; cfr. Calabresi, Concerning Cause and the Law of Torts, en 43 Chi. L. Rev. 69, 69 n. 1, 1975).

De hecho, en el derecho de torts la causalidad constituye un requisito indispensable a efectos del resarcimiento del daño. Cause-in-fact, factual cause, actual causation o but-for test son algunas expresiones de que se vale la doctrina norteamericana cuando hace referencia al concepto de causalidad -si bien el requisito de causalidad ha sido descrito por William Posser, una autoridad en materia de torts, como uno de los problemas más simples y aparentes en la determinación de la responsablidad- en realidad se ha sobrepuesto al esfuerzo de reducir la noción a una fórmula de fácil comprensibilidad y se ha constuido con opiniones diversas con respecto a su naturaleza, fin y significado. Durante los primeros años del presente siglo los jueces han aplicado una noción muy lata de causalidad y de este modo han hecho uso del término para referir no sólo el hecho de que la conducta dañosa del demandado ha contribuido a ocasionar el daño, sino también el caso de que se pueda considerar al demandado responsable del daño a la luz de otros elementos. No obstante, hacia el segundo cuarto de siglo los juristas del realismo norteamericano han insistido en relacionar el problema causal sólo a cuanto concierne a la actual causation o cause-in-fact, es decir, a la investigación dirigida a determinar si la conducta del demandado ha contribuido a la producción del daño (véase R. Wright, cit., p. 1737).

Cause-in-fact, como se lee en la doctrina norteamericana, representa una investigación compleja de Ios hechos cuyo objetivo es individualizar los eventos que han dado lugar al daño. La investigación de la causalidad lleva a establecer si el hecho del demandado ha sido el que ha ocasionado el daño. Por el contrario, se trata del elemento que permite al demandado exonerarse de la responsabilidad si su hecho dañoso no ha sido causa del daño sufrido por la víctima (cfr. Wex S. Malone, Ruminations on cause-in-fact, en 9 Stan. L. Rev., 1956, p. 60; E. Price, Toward a Unified Theory of Products Liability: Reviving the Causative Concepto f Legal Fault, en 61 Tenn. L. Rev., 1994, p. 1347).

El test más difundido en la determinación de la cause-in-fact, a efectos de la imputación de la responsabilidad, es conocido como el but-for test. Según este test una cierta conducta (sea acción, omisión, condición, etc.) ha sido la causa de un daño sólo si éste no se habría producido cuando aquélla no se hubiera realizado.

Por ende, el elemento de la condición necesaria parece ser fundamental en la investigación de la causalidad. La conducta dañina debe haber sido una condición necesaria para la producción del daño (Wright, cit., p. 1775).

Como se puede observar, nos encontramos frente al examen de la llamada causalidad de hecho que no es más que la fase de la reconstrucción de la causalidad que permite determinar al responsable del hecho ilícito. Como es sabido, la segunda fase en el análisis del proceso causal es el de la causalidad jurídica, en la cual es dable establecer la entidad de las consecuencias perjudiciales del hecho de que se traducen en el daño resarcible. Así, es oportuno hablar de causalidad de hecho cada vez que se trate de examinar la vinculación entre los elementos del ilícito, es decir, la conducta y el evento (véase para una profundización sobre la materia de la causalidad: M. Franzoni, Dei fatti illeciti, en Comm. Cod. Civ. Scialoja-Branca, Zanichelli editore, Bologna, 1993, p. 2041 ss.).

Los casos DES nos presentan un problema de causalidad de hecho. En efecto, las circunstancias en que se produjeron los daños, entre los cuales la exsitencia de cientos de productores del fármaco, el descubrimiento de los efectos dañinos muchos años después de que las madres de las víctimas 
habían ingerido el DES, ponen a las víctimas en una situación de dificultad o, mejor dicho, de sustancial imposibilidad al individualizar al responable de la puesta en circulación de la sustancia defectuosa. Y como se deduce de las sentencias, cuyos pasajes han sido transcritos precedentemente, los jueces norteamericanos nos enseñan que existen casos en materia de torts en que la prueba de la causalidad se reputa no necesaria. Un claro ejemplo es dado por los casos DES para cuanto se refiere a la responsabilidad del productor.

Si bien la teoría de la market liability fue aplicada inicialmente a los casos DES, queda el hecho de que se exonera a la víctima de probar un hecho fundamental a la luz de la teoría tradicional de la responsabilidad civil, es decir, el nexo de causalidad. Este hecho deviene por sí mismo un precedente que debe ser considerado con mucha cautela, si no se quiere resbalar hacia el abismo de la responsabilidad absoluta.

Con una concepción probabilísitica de la causalidad, como aquélla sobre la cual se construye la teoría de la market-share, uno se aleja ineluctablemente de los principios que rigen la responsabilidad civil para dar una respuesta inmediata en los casos concretos de dificultad probatoria del nexo causal. Además, mientras es verdad que esta dificultad comporta para la víctima la imposibilidad de obtener el resarcimiento de los daños, no se puede negar que es igualmente injusto imponer una responsabilidad al productor que no ha ocasionado el daño y, en consecuencia, deviene una suerte de aseguración de los daños ocasionados por otros. Se le impone así un rol que es completamente diverso de aquél que se le pide, esto es, garantizar la seguridad de sus productos.

Por otro lado, parece que se puede afirmar que tales teorías fundadas en una concepción probabilística de la causalidad pueden ser utilizadas en cualquier otro caso en materia de responsabilidad del productor en que la víctima se encuentre frente a la dificultad de individualizar al responsable de los daños. 